\title{
Mapeamento da cultura do design de jogos a partir do seu contex to histórico
}

\section{Mapping the culture of game design from its historical context}

\section{NAPOLEÃO, Eduardo}

Universidade do Vale do Itajaí - UNIVALI I eduardonapoleao@univali.br

\section{BRAVIANO, Gilson}

Universidade Federal de Santa Catarina - UFSC I gilson@cce.ufsc.br

VIEIRA, Milton Luiz Horn

Universidade Federal de Santa Catarina - UFSC I milton.vieira@ufsc.br

\begin{abstract}
Resumo
O presente artigo busca apresentar um enfoque cultural dos jogos enquanto mídia, em manifestações digitais e não digitais, mapeando-os enquanto uma ferramenta de significação cultural. Durante a pesquisa, foi possível identificar influências culturais diversas que contribuíram para a construção da cultura de jogos, considerando seus aspectos tangíveis e intangíveis. Assim, entende-se que a relação entre jogos e a cultura, e a forma como seu design foi influenciado por diferentes práticas e costumes, permitiu o desenvolvimento de uma cultura específica de jogos.
\end{abstract}

Palavras-chave: Design de jogos. Cultura de jogos. Jogos e mídia. Jogos digitais.

\section{Abstract}

This paper presents a cultural approach of games as a medium, in both digital and non-digital representations, by mapping games as tools to convey cultural significance based on their design. During the research, it was possible to identify many cultural influences that contributed to the construction of the game culture, considering its tangible and intangible aspects. Thus, we understand that the relationship between games and culture - and the way in which design was influenced by different practices and habits - has impacted the development of a specific game culture.

Keywords: Game design. Game culture. Games and media. Digital games. 


\section{INTRODUC̣ÃO}

Os jogos são aplicados como elementos da cultura desde muito tempo. A forma de jogá-los e suas aplicações sociais sofreram influência de diferentes sociedades ao longo da história e afetaram dinâmicas de funcionamento das mesmas, incluindo mudanças no desenvolvimento de processos intelectuais, a invocação de rituais e a busca de conexões forçadas entre passado e futuro (FLANAGAN, 2009).

Ao longo do tempo, o desenvolvimento da indústria de materiais gráficos e a popularização de board games e card games ajudaram a massificar o mercado de jogos não digitais e sua aplicação social entre famílias, geralmente associadas a momentos de lazer. Nos Estados Unidos, uma das marcas que mais produziu jogos não digitais entre os séculos XVIII e XIX foi a Parker Brothers.

Para Flanagan (2009), os jogos, utilizados enquanto uma mídia de exploração e expressão cultural, tendem a manifestar em suas aplicações a influência de determinadas culturas a partir de suas regras, mecânicas, artes, histórias e interações e, por vezes, influenciam a própria cultura, gerando novos mecanismos de interação que podem ser sociais, artísticas, e também comportamentais. Tendo em vista os aspectos citados, esse estudo busca apresentar um enfoque cultural dos jogos enquanto mídia, em manifestações digitais e não digitais, mapeando-os enquanto uma ferramenta de significação cultural, terminando por gerar uma cultura específica.

A arte datada de 1560 do artista Pieter Bruegel chamada Khinderspil, ou "jogos das crianças" (Figura 1), inclui a representação de mais de noventa jogos comuns para a época (FLANAGAN, 2009). A intenção do artista em relatar essas diversas formas, conforme afirma Bogost (2015) ao citar pesquisadores como Johan Huizinga e Brian Sutton-Smith, tem o objetivo de demonstrar que jogar é um ato central da atividade humana, e não uma ação acessória.

Figura 1 - Khinderspil, de Pieter Bruegel

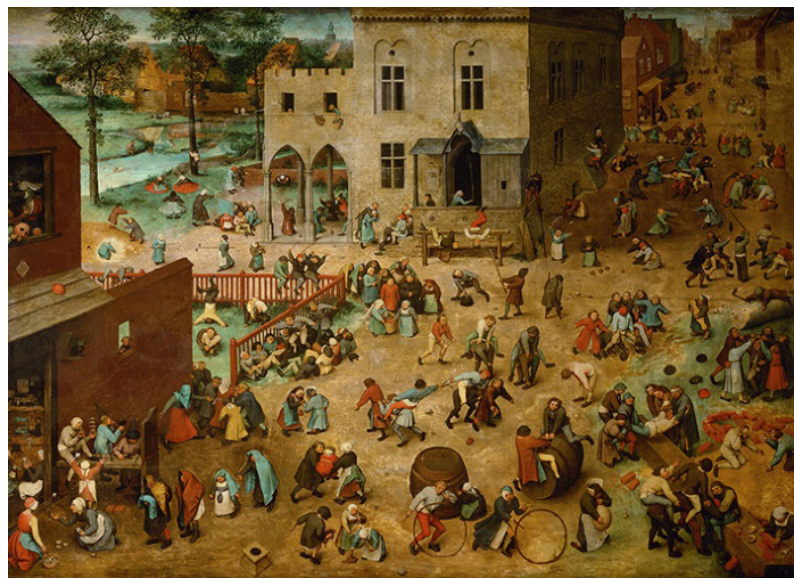

Fonte: Wikimedia Commons (2017). 
Observa-se a partir da arte de Pieter Bruegel, que a construção da cultura é influenciada pelo uso dos jogos, e ambas dependem das diferentes interpretações emanifestações coletivas proporcionadas paraodesenvolvimento e evolução de seus conceitos específicos. Durante o desenvolvimento dos jogos não digitais, alguns apresentaram experiências mais abstratas, como o gamão. Nessa categoria também é possível incluir os jogos Xadrez e Go, apesar das referências culturais de suas regiões de origem ou de suas relações com estruturas sociais dominantes à época do seu desenvolvimento. Considera-se que o primeiro é influenciado por culturas existentes na idade média europeia, e o segundo por culturas asiáticas. Assim, a abstração de mecânicas proporciona uma qualidade universal para essas experiências de jogo, permitindo que estes possam ser compreendidos por várias regiões, religiões e culturas. Dessa forma, alguns jogos de tabuleiro abordam preocupações sociais gerais, enquanto outros consideram eventos mundanos em suas relações práticas (FLANAGAN, 2009).

Em jogos digitais, é possível perceber que a significação de elementos e ícones que devem ser interpretados durante o jogo é muito usada como forma de construção simbólica das ações de jogos entre os jogadores e, também, entre a inteligência artificial que controla o jogo e o jogador. Nesse sentido, ícones que buscam representar a ideia de alimentos, por exemplos, tornaramse símbolos universais de saúde em jogos, como a representação visual de cogumelos em jogos como Minecraft e Super Mario Bros e a representação visual de sopas na franquia The Legend of Zelda (HANSEN, 2016). Dessa forma, em muitos casos, jogos influenciam e são influenciados por contextos culturais, e que essa manifestação acontece em ambientes digitais e também não-digitais.

Outros acontecimentos relacionados com a cultura dos jogos acabam afetando a cultura como um todo. O jogo E.T. The Extra-Terrestrial, desenvolvido para o console Atari 2600 no início da década de 1980, por exemplo, é reconhecido pelo fato de que vários dos seus cartuchos produzidos foram enterrados em um aterro sanitário na cidade Alamogordo (Novo México), nos Estados Unidos, durante o início dos anos 1980 (HANSEN, 2016). Esse fato foi questionado enquanto verdade ou ficção até a realização de um documentário sobre as escavações do aterro sanitário, no qual os produtos, muitas vezes ainda lacrados em suas caixas originais, foram encontrados (VON DOVIAK, 2015). Devido às dúvidas populares pode-se afirmar que uma cultura de jogos foi gerada em torno desse boato, afetando a mídia e a marca E.T. The ExtraTerrestrial em seus valores tangíveis e intangíveis.

Assim, jogos são formas legítimas de mídia, expressão humana e relevância cultural, pois afetam crenças, regras e comportamentos das culturas nas quais são envolvidos. Compreender sua cultura, assim com a forma como eles afetam e são afetados por outros elementos sociais é um caminho possível para o entendimento da maneira como os seres humanos interagem socialmente e geram significado a partir dessas mídias (FLANAGAN, 2009). 
O presente artigo busca apresentar um enfoque cultural dos jogos enquanto mídia, em manifestações digitais e não digitais, mapeando-os enquanto uma ferramenta de significação cultural, terminando por gerar uma cultura específica. Considerando-se uma perspectiva interdisciplinar, os jogos são uma mídia de interpretação cultural, criação e modificação ativa da mesma, inseridos em um processo de desenvolvimento não-linear.

Como forma de estruturar o presente artigo, os autores buscaram apresentar a mídia jogos a partir de sua organização histórica. Considerouse inicialmente uma perspectiva não digital e, posteriormente, outra digital, embora ambas coexistam em alguns períodos. Dessa forma, em um primeiro momento, observa-se alguns exemplos culturais de jogos na África, Ásia e Europa, além da sua chegada na América, e a forma como a mídia foi utilizada nessas diferentes regiões. Em um segundo momento, apresenta-se o nascimento e desenvolvimento da cultura digital dos jogos, com um foco nos produtos americanos e japoneses. É a partir desse contexto histórico, linearizado e regionalizado, que a pesquisa busca organizar seu pensamento cultural e atingir o objetivo proposto para o mesmo.

\section{JOGOS NÃO DIGITAIS}

Jogos conhecidos como boardgames, jogos de mesa outambém tabuleiros parecem, em um contexto inicial, materializar a abstração de espaços de caça e agricultura, assim como a divisão de terras e a invenção de áreas de irrigação, além de sua relação com geometria e matemática em um contexto de processos mentais. Esses terrenos de jogo simbólicos afetam diretamente as relações humanas, tanto sociais quanto físicas (FLANAGAN, 2009). Considerando uma abordagem focada na cultura de jogos e no entendimento do produto enquanto mídia, pode-se afirmar que os board games são um dos materiais essenciais da cultura a partir dos quais podemos analisar e compreender práticas sociais culturais, crenças e comportamentos. Num primeiro momento, eles abordavam questões como a agricultura e crenças religiosas. Para o autor em questão, além das questões culturais e sociais envolvidas no desenvolvimento e prática desses jogos, eles continuam a influenciar seus derivados contemporâneos devido aos padrões de jogo, regras e mecânicas desenvolvidas. Alguns dos exemplos mais antigos estão relacionados com as próprias civilizações do passado. Senet (Figura 2) e Jogo de Ur são encontrados em áreas como Egito, Palestina, Iraque e Irã, além do jogo Mancala, originário do continente africano. 
Figura 2 - Senet.

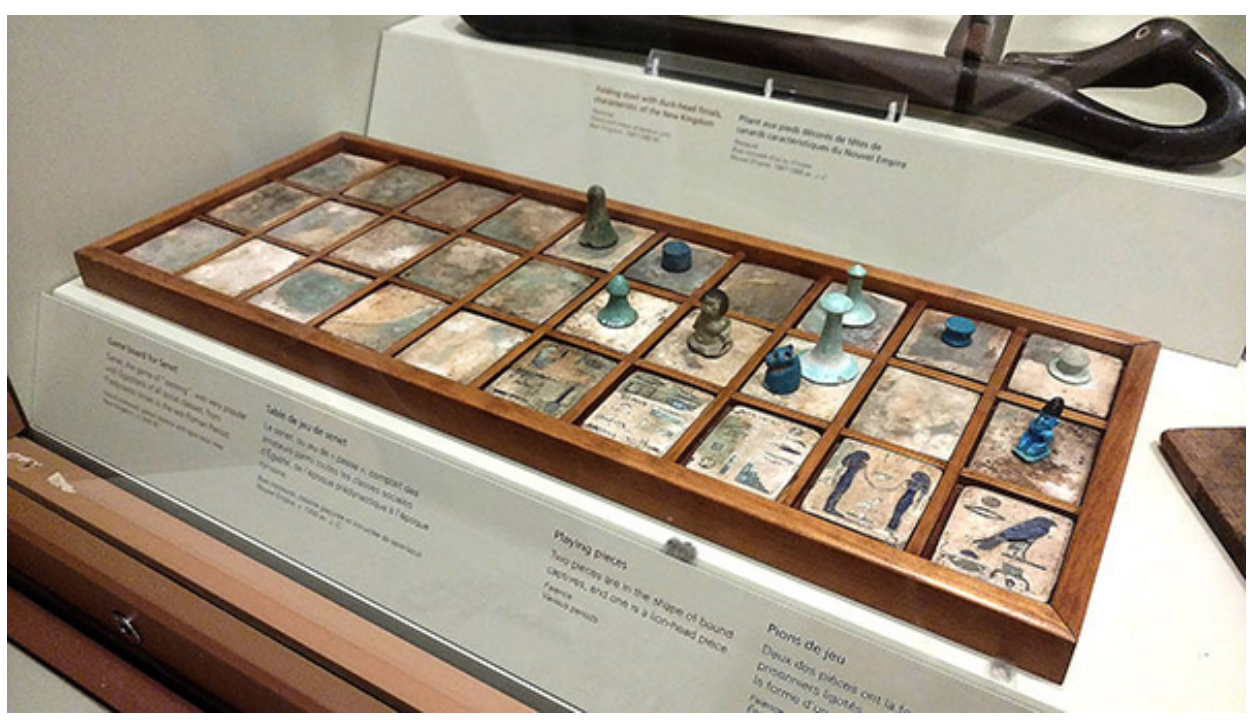

Fonte: Do autor.

Para Flanagan (2009) há evidências de que os jogos antigos que envolviam mecânicas e regras relacionadas com sorte frequentemente possuíam importância espiritual e ritualística. Os tabuleiros do jogo egípcio Senet (3500 a.C.) eram desenhados para dois jogadores e apresentavam regras relacionadas com a sorte. O próprio significado do nome Senet pode estar relacionado com a ideia de passagem, pois o mesmo deveria ser jogado durante a jornada para um mundo pós morte. Para o autor, era considerado uma mídia de caráter social.

Acredita-se que o jogo conhecido no Japão como Go e na China como Weigi é derivado de práticas divinas realizadas por imperadores e astrólogos da cultura Zhou (Figura 3). Flanagan (2009) cita o historiador de jogos David Parlett, o qual afirma no seu livro Oxford History of Board Games que o significado de coletar peças brancas e pretas está relacionado com uma representação simbólica do céu ou da terra e do céu, relacionada ainda com os padrões resultantes da prática, além da divisão em quatro áreas que simbolizam as quatro estações.

Figura 3 - Go.

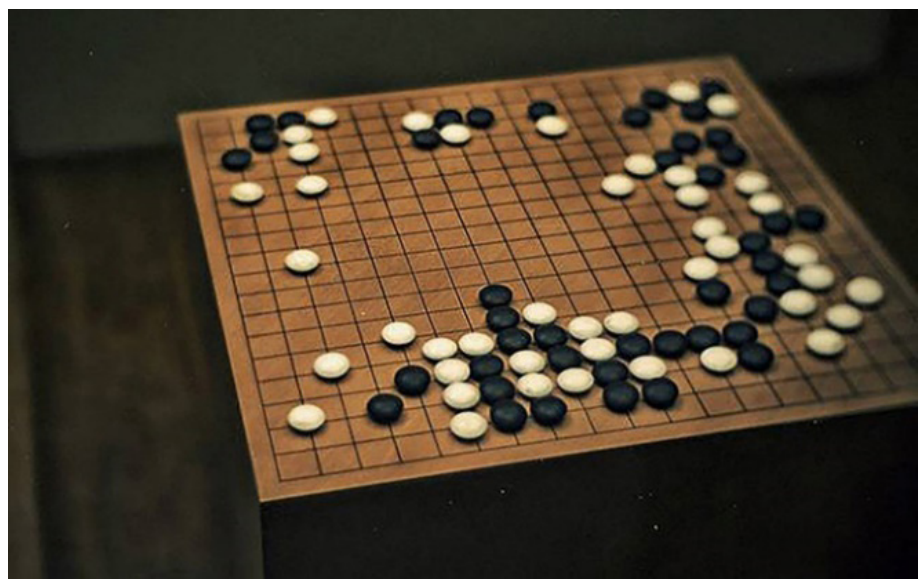

Fonte: Moreira (2017).

Projética, Londrina, v.9, n.1, p. 123-138, Jan./Jun. 2018 
Os jogos de tabuleiro tornam-se ainda mais populares com a difusão da impressão em larga escala. Jogos de carta, por exemplo, são citados na China e na Ásia por volta do ano 1294 d.C., e suas temáticas envolviam religião, política, atores, monstros, samurais e vida doméstica, representando inclusive situações como o processo de vestir uma armadura, sendo este um jogo de Utagawa Yoshikazu (FLANAGAN, 2009). No contexto europeu, observa-se a influência das culturas africanas e asiáticas no desenvolvimento dos produtos. Entretanto, a influência da igreja fica mais evidente na tentativa de proibição de um jogo de dados chamado Tables. Outra evidência pode ser citada em relação à nomeação de peças do xadrez, envolvendo a utilização de peças que representavam, simbolicamente, bispos, reis e rainhas, dentre outros.

Flanagan (2009) cita que, para H. J. R. Murray em seu livro A History of Board Games Other Than Chess, originalmente publicado em 1951 pela Oxford University Press, o interesse cultural pelos jogos e o relato cultural de suas práticas em seus respectivos países começou apenas no século XIII na Europa. Alguns dos mais significativos jogos são o xadrez e o gamão.

No século XIX, board games começam a se tornar parte da cultura na América do Norte a partir da prática e jogos de tabuleiro, jogos de cartas e outros jogos com características indoors. Após a Guerra Civil americana, há o registro de um número crescente da criação e desenvolvimento de jogos de caráter comercial (FLANAGAN, 2009). Para o autor, os board games podem despertar paixões nacionais, podem se tornar espaços de crítica social e também prover plataformas de instruções religiosas. Com a revolução da impressão no Japão e Ásia, esses jogos foram produzidos em massa, o que facilitou sua difusão e inclusive o desenvolvimento de versões portáteis dos jogos. A produção em massa desses produtos impressos só aconteceu nos Estados Unidos e na Europa durante o século XIX, com um grande atraso em relação à produção asiática. Ainda de acordo com o mesmo, na América do Norte, eles continuaram proporcionando a exemplificação de valores, crenças e costumes, mas em um contexto iniciais de imigração, urbanização e crescimento industrial. A classe média, que experimentava um momento de crescimento financeiro e de mais tempo disponível para o lazer, encorajava as crianças a jogarem com o objetivo de desenvolver nelas habilidades de raciocínio e instruções morais.

Exemplos intactos de jogos desenvolvidos no século XIX nos Estados Unidos são raros. Motivos variados como baixa qualidade na impressão original, levando ao desgaste e fragmentação das peças originais, e também o senso cultural de que esses produtos, vistos como brinquedos àquela época, não eram objetos de necessária preservação (FLANAGAN, 2009). Apesar disso, existem museus que buscam preservar a cultura de jogos desse período, assim como sítios digitais que descrevem, organizam e criticam esses produtos. Grant (2015), por exemplo, busca explicitar a forma como Credity Ability e Park 
and Shop (Figuras 4A e 4B) buscaram educar os americanos nas questões e habilidades relacionadas às compras, considerando o desenvolvimento do comércio e das estruturas sociais vigentes.

Figura 4 - Jogos Credity Ability e Park and Shop.

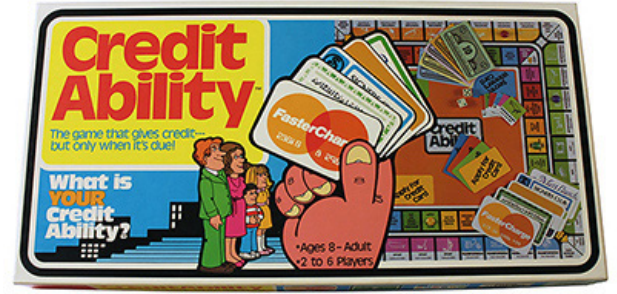

A

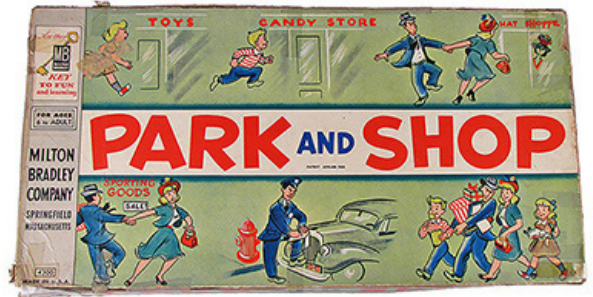

B

Fonte: Grant (2015).

Conforme Flanagan (2009), a primeira produção em massa significativa de board games nos Estados Unidos focou em temas relacionados à vida doméstica. Assim, os primeiros produtos desenvolvidos por grandes fabricantes apresentavam temas como religião, vida doméstica e instruções morais. Em um segundo momento, outros temas foram acrescentados, como economia e guerra, além de jogos abstratos. Marcas como Parker Brothers desenvolveram jogos como Tiddlywinks (1897) (Figura 5 A), Post Office Game (1897) (Figura 5 B), e War at Sea (1898). Como outros jogos da época, essas mídias abordavam costumeiramente temas morais como "o bom versus o mau".

Figura 5 - Tiddlywinks (1897) (Figura 5 A), Post Office Game (1897) (Figura 5 B).

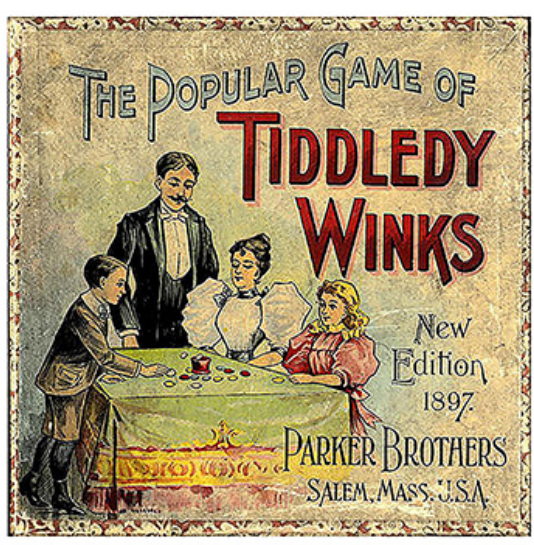

A

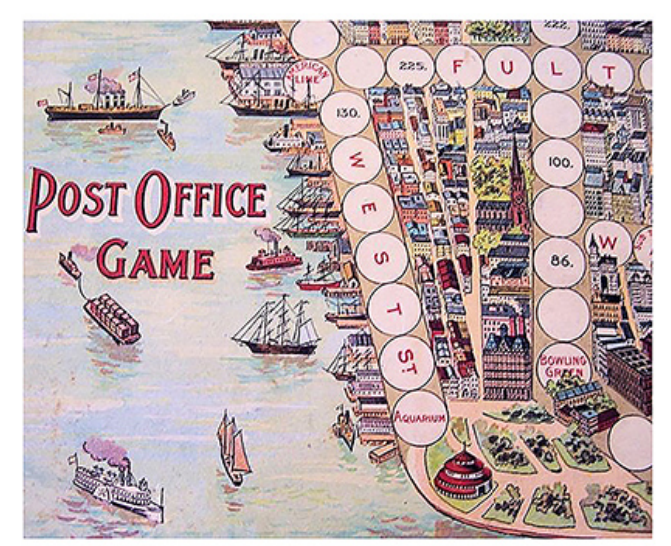

B

Fonte: Do autor (2017).

Outro jogo desenvolvido pela empresa Parker Brothers, chamado The Game of Playing Department Store, publicado em 1898 possuía sua condição de vitória ou derrota baseada na capacidade dos jogadores em comprar a maior quantidade possível de bens durante uma ida a loja de departamentos. No final do século XIX, a crença cultural de que riqueza era sinônimo de sucesso na América era uma característica refletida também pelas suas mídias de 
entretenimento (FLANAGAN, 2009). Como parte dessa característica cultural, no início do século XX, a marca Parker Brothers lançou sua primeira versão do jogo Monopoly, em 1933, vendendo aproximadamente 500 mil cópias do produto em dois anos. É importante afirmar que o produto lançado pela empresa é na verdade uma adaptação de um outro board game, originalmente patenteado por Lizzy Magie em 1903 e chamado de Landlord's Game (PILON, 2015).

Conforme Flanagan (2009), enquanto os jogos desenvolvidos nos Estados Unidos focaram em determinados tipos de comportamento e condições morais, os board games europeus do mesmo período buscavam retratar eventos históricos e representar o folclore de determinadas regiões. Na França, foi lançado o produto Jeu de la Revolution (Figura 6), na década de 1850, como uma variação de um outro, chamado Snakes and Ladders. Assim, de acordo com o autor, um clássico foi transformado com o objetivo de propagar crenças racistas e justificativas para o colonialismo. Apesar de aparentar um tipo de diversão inocente quando foi lançado, este buscava representar estereótipos raciais a partir de suas relações práticas, considerando o seu uso como forma de educar e informar através de suas regras e mecânicas.

Figura 6 - Jeu de la Revolution.

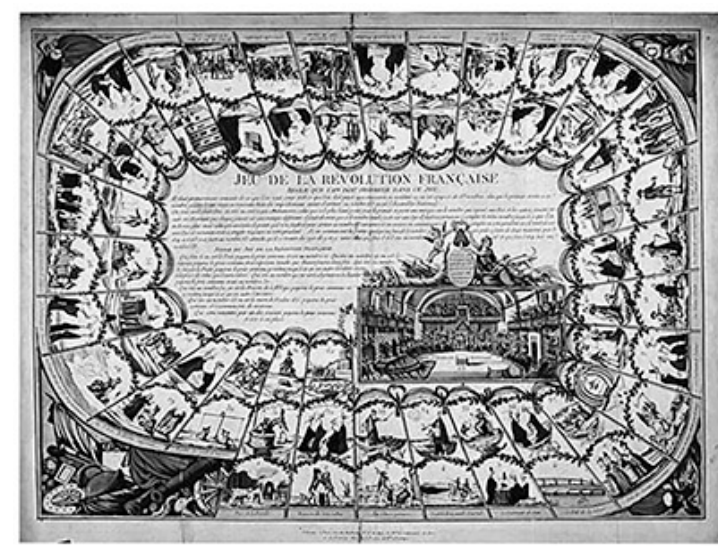

Fonte: Flanagan (2009).

\section{O NASCIMENTO DA CULTURA DIGITAL DOS JOGOS}

A partir dos anos 1950, a cultura de jogos estava envolvida com um novo paradigma: a mudança de um contexto não digital para um contexto digital. Além do desenvolvimento tecnológico, a Corrida Espacial e a Guerra Fria influenciaram tanto o desenvolvimento da tecnologia necessária para que essa mudança acontecesse como ajudaram a inspirar a identidade visual e histórias dos produtos desenvolvidos à época. Hansen (2016) cita alguns exemplos como o desenvolvimento de Spacewar em 1960 nos Estados Unidos, o envio pelos russos do primeiro homem para o espaço em 1961 e o fato de o primeiro homem 
caminhar na Lua em 1969. Paralelamente, o primeiro mouse de computador foi inventado em 1964, e a primeira calculadora portátil foi criada em 1967, assim como o primeiro uso da internet, nos Estados Unidos, em 1969. Nesse contexto cultural, A empresa Atari é criada em 1972. Naquele ano, de acordo com o autor, Nolan Bushnell instalou uma máquina do tipo arcade do jogo Pong, que simulava uma partida de tênis, em um bar na Califórnia. O sucesso da máquina do tipo arcade, influenciado pelo contexto cultural vigente, acabou por modificar o comportamento das pessoas em relação aos jogos, assim como o processo de criação e desenvolvimento dos mesmos. Um dos exemplos da influência de Pong na cultura popular contemporânea pode ser vista no filme animado de 2008 WALL-E, da marca Disney. Em uma das cenas do audiovisual é possível, inclusive, observar a interação do personagem principal com o jogo.

Assim, conforme Flanagan (2009), para essa nova geração, a mudança comportamental não foi somente relacionada à cultura de jogos não digitais vigentes à época, mas também uma mudança de comportamento intelectual e social redefinidas pela mudança do espaço físico nos qual as experiências passaram a acontecer, sendo executados em casas, mas agora também mediados pelas máquinas em bares e cafés. De acordo com Ashcraft (2012), considerando o Japão, jogos como Space Invaders (1978), Pac-Man (1980), Donkey Kong (1981) e Street Fighter II (1991) ajudaram a moldar essa cultura (Figura 7). Para Hansen (2016), o relacionamento entre as empresas Midway Games e a marca de origem japonesa Taito ajudou a impulsionar o mercado de máquinas de jogos do tipo arcade nos anos 1970.

Figura 7 - O uso de arcades na cultura japonesa.

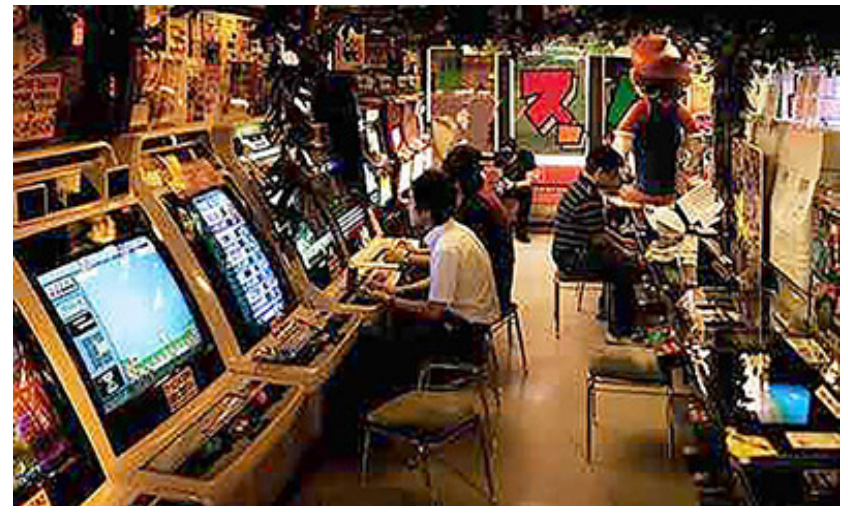

Fonte: Ashcraft (2012).

Além dos arcades, houve o desenvolvimento da cultura de desenvolvimento e venda de produtos publicitários relacionados aos jogos, como camisetas, doces, lancheiras, posters, músicas e programas de televisão. Assim como hoje, a cultura de criação, desenvolvimento e uso de produtos e serviços relacionados à cultura dos jogos ajudou a criar o imaginário em torno dessa mídia. Para o autor, o primeiro grande sucesso da cultura de merchandising relacionada foi o jogo Pac-Man, já no início dos anos 1980. Considera-se 
como parte do motivo o desenvolvimento e caracterização do design de um personagem, assim como de sua história, sendo o personagem considerado o primeiro mascote da indústria digital de jogos.

\section{A CULTURA DE GAMES MEDIADA PELO USO DE MASCOTES}

O desenvolvimento de mascotes e a estratégia de marcas de videogames associadas à utilização dos mesmos como parte do seu imaginário pode ser observado a partir da metade dos anos 1980. Nesse contexto, a marca Nintendo, a partir do designer Shigeru Miyamoto, foi uma das mais bem-sucedidas da época, ajudando a criar uma nova cultura de jogos a partir da exposição mundial da indústria de videogames japonesa, que influenciou a indústria não somente a partir da criação de personagens e histórias, como de inovações tecnológicas (desenvolvendo novos consoles e tecnologias para os cartuchos) e mecânicas interativas, com a introdução do botão de pulo no jogo Donkey Kong, em 1981. Outros indícios das influências culturais da indústria de jogos japonesa na cultura contemporânea são o uso de suas músicas fora do contexto de game music e o fato de que, hoje, o personagem Mario (desenvolvido pela empresa Nintendo nos anos 1980 e utilizado em inúmeros jogos), é mais reconhecido pelas crianças americanas do que Mickey Mouse, desenvolvido pela marca Disney, conforme Hansen (2016). Para o autor, orquestras tocaram as músicas do personagem em questão, óperas foram escritas e cantaram sobre ele e, além da criação do seu próprio cartoon e filme, sua música é utilizada como parte dos elementos sensoriais de entretenimento em partidas de basquete, vídeos musicais e comerciais de televisão.

A influência japonesa a partir da guerra de mascotes ficou caracterizada pela disputa de liderança do mercado mundial, nos anos 1990, entre as marcas japonesas Sega e Nintendo, representadas pelos consoles Gênesis (ou Mega Drive) e Super Nintendo (ou Super Famicom). Ambas utilizaram o desenvolvimento de mascotes como principal estratégia de marca do período, sendo os personagens Sonic (Figura 8 A) e Mario (Figura 8 B) os seus principais representantes, respectivamente (HARRIS, 2014).

Figura 8 - Mascotes Sonic e Mario.

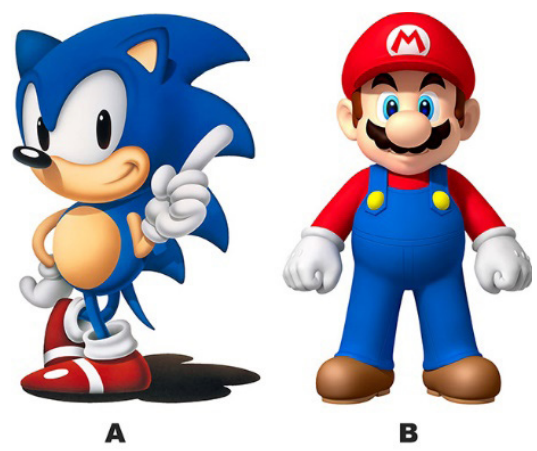

Fonte: Do autor. 
A marca Nintendo continuou associando personagens a sua marca ao longo dos anos, influenciando a cultura dos jogos a partir da inserção e manutenção de novos personagens em suas mídias digitais e não digitais, além do desenvolvimento de estratégias envolvendo marcas de diferentes setores. Hausen (2016) cita o exemplo da utilização pela Nintendo da marca Pokemón, a partir do final da década de 1990, principalmente a partir do uso de seu personagem principal, chamado Pikachu. para o autor, essa parceria pode evidenciada em diversas mídias digitais e não digitais, como no carro New Beetle amarelo desenvolvido em conjunto com a marca Volkswagen, no fato de o personagem Pikachu ser o segundo colocado no ranking elaborado pela revista TIME "Best People of 1999", no uso da imagem do personagem pela marca All Nippon Airways como forma de identificar os seus aviões a partir do ano 1998 (Figura 9), e também no uso do personagem como mascote oficial da seleção japonesa de futebol durante o evento Copa do Mundo de 2014. Considerando a mídia jogos digitais, foram lançados aproximadamente 122 jogos desde 1996, sendo o primeiro deles para o console portátil Game Boy, da marca Nintendo (FRANK, 2016).

Figura 9 - Uso do personagem Pikachu em carros e aviões.
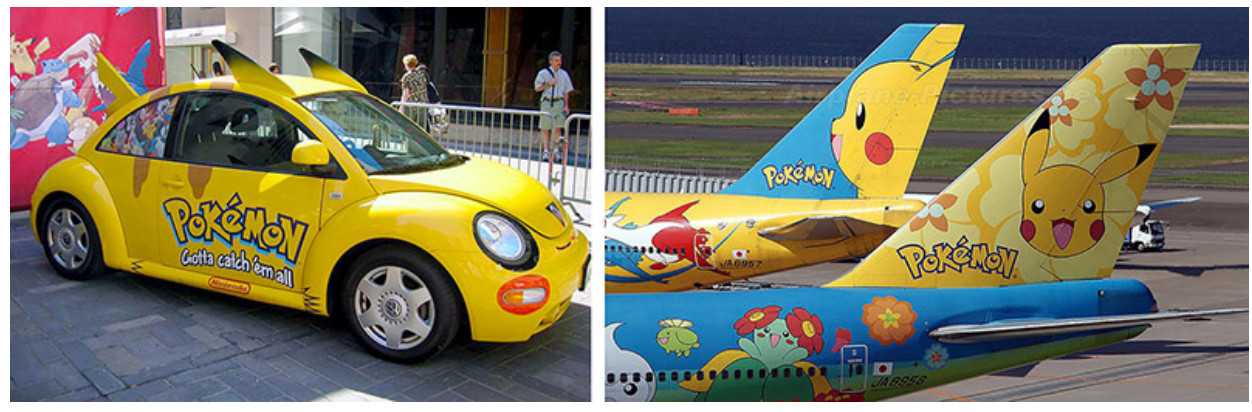

Fonte: Do autor.

\section{AMADURECIMENTO DA INDÚSTRIA TECNOLÓGICA E INFLUÊNCIAS DO MUNDO DIGITAL NA CULTURA DE JOGOS}

Os anos 2000 foram marcados pelo aumento do uso da internet, além da modernização e evolução dos dispositivos tecnológicos. Para Flanagan (2009), os jogos modernos pareciam convidar jogadores e designers a criar utopias domésticas de imaginação cultural, considerando estilos já documentados. Conforme o autor, nesse momento os jogadores criaram e recriaram, através dessa mídia específica, suas experiências de jogo baseadas em fatores diversos, reescrevendo mundos populares e oferecendo suas próprias interpretações do ato, em contraste com as primeiras culturas que possuíam regras mais rígidas quanto a essas questões, geralmente abordando temas como agricultura e religião. Um dos principais exemplos desse período é o jogo The Sims, desenvolvido pela empresa Max e concluído no ano 2000, buscando proporcionar para os jogadores a metáfora de uma casa virtual, na 
pode-se controlar, modificar e personalizar áreas de uma residência, assim como seus moradores e objetos (ISBISTER, 2016). Para Flanagan (2009), o jogo é um sítio de constantes negociações entre as experiências domésticas reais e virtuais, considerando que tanto a experiência interativa assim como a brincadeira infantil de simular um ambiente doméstico são mecanismos de fantasia importantes nesse contexto cultural.

Considerando a personificação de caracteres, é possível citar a personagem Lara Croft, a qual tornou-se um ícone da cultura popular, aparecendo na capa do jornal Financial Times, a principal mídia impressa para business nesse formato do Reino Unido. Além disso, ela pode ser encontrada em revistas como Time, Newsweek, The Face (principal revista de moda da Europa) além de outras, referentes à cultura de jogos. Foi associada também a marcas como Visa, bebidas energéticas, carros esportivos, tornou-se um selo francês e foi utilizada durante a turnê PopMart do conjunto musical U2 (HANSEN, 2016).

Em 2001, a produção do jogo GTA III, desenvolvido pela marca Rockstar Games e ambientado em uma área inspirada na cidade Nova lorque, chamada nesse mundo fictício de Liberty City, foi afetado pelo ataque terrorista às Torres Gêmeas. Esse acontecimento de proporções globais fez com que a empresa responsável pelo produto digital mudasse a data de lançamento do mesmo e realizasse algumas alterações em seu enredo, já que as novas condições culturais haviam transformado a forma como os jogadores poderiam interpretar e conduzir suas ações nesse ambiente. Assim, os carros de polícia tiveram que ser visualmente modificados com o objetivo de diminuir a semelhança entre os mesmos e os carros oficiais da polícia de Nova lorque (PHILLIPS, 2011). Além disso, uma das missões, que estava relacionada com o uso de aviões, foi retirada da versão final do produto. O uso de caracteres não jogáveis que representavam idosos e crianças pedestres foi alterado a partir da remoção dos mesmos das ruas da cidade fictícia, dentre outras questões. Apesar das alterações, a reação das pessoas quanto à experiência proposta foi considerada mista, devido aos níveis de violência presentes percebidos no produto, afetando inclusive o seu processo de vendas em lojas como a rede americana de mercados Walmart (HANSEN, 2016).

Na segunda metade da década de 2010, com a chamada Revolução Casual, em conjunto com o desenvolvimento tecnológico e o lançamento e popularização dos smartphones, novas possibilidades culturais foram apresentadas ao mercado, envolvendo o surgimento de novos desenvolvedores, marcas e possibilidades de aplicação da cultura de jogos (JULL, 2010). Produtos interativos como Dance Dance Revolution, originalmente aplicados com o objetivo de diversão, passam a ser utilizados como uma ferramenta de educação física para crianças (SCHIESEL, 2007). Jogos diversos passam a ser aplicados também em contextos de treinamento de equipes ou simulação de risco de negócios em empresas (VILHELMSEN, 2017). Além disso, transformam-se em mídias que objetivam expressar e proporcionar a experiência de questões relacionadas à empatia (BARTELSON, 2017), como no jogo "That Dragon, Cancer", que apresenta 
a história de um garoto com câncer terminal. A cultura de jogos modifica-se ao ponto que é inaugurado em 2011 o site de streaming de vídeos "Twitch. tv". Comprado pela marca Amazon em 2014 funciona como uma "televisão" interativa de jogos, proporcionando espaços de debates sociais principalmente relacionados à cultura em questão (GANDOLFI, 2016).

Jogos podem ajudar no processo de engajamento e motivação para a solução de problemas e conclusão de tarefas e conquista de objetivos. Para McGonigal (2011) a ação de jogar o jogo World of Warcraft é de certa forma agradável que os jogadores desse jogo gastaram em grupo aproximadamente 6 milhões de anos executando tarefas e realizando missões nesse ambiente de jogo. A autora afirma que mais tempo foi gasto em jogos da respectiva marca do que os seres humanos gastaram evoluindo enquanto espécies.

Essas novas possibilidades culturais relacionadas à mídia jogos afetam inclusive não só o produto final, mas seu desenvolvimento em si. Para Silveira (2016), uma das etapas de design necessárias para o desenvolvimento do jogo Never Alone (Figura 10), produzido pela empresa Upper One Game, foi a realização de um processo de uma semana de imersão dos designers junto à membros da cultura Iñupiat, representados na história do jogo.

Figura 10 - Never Alone.

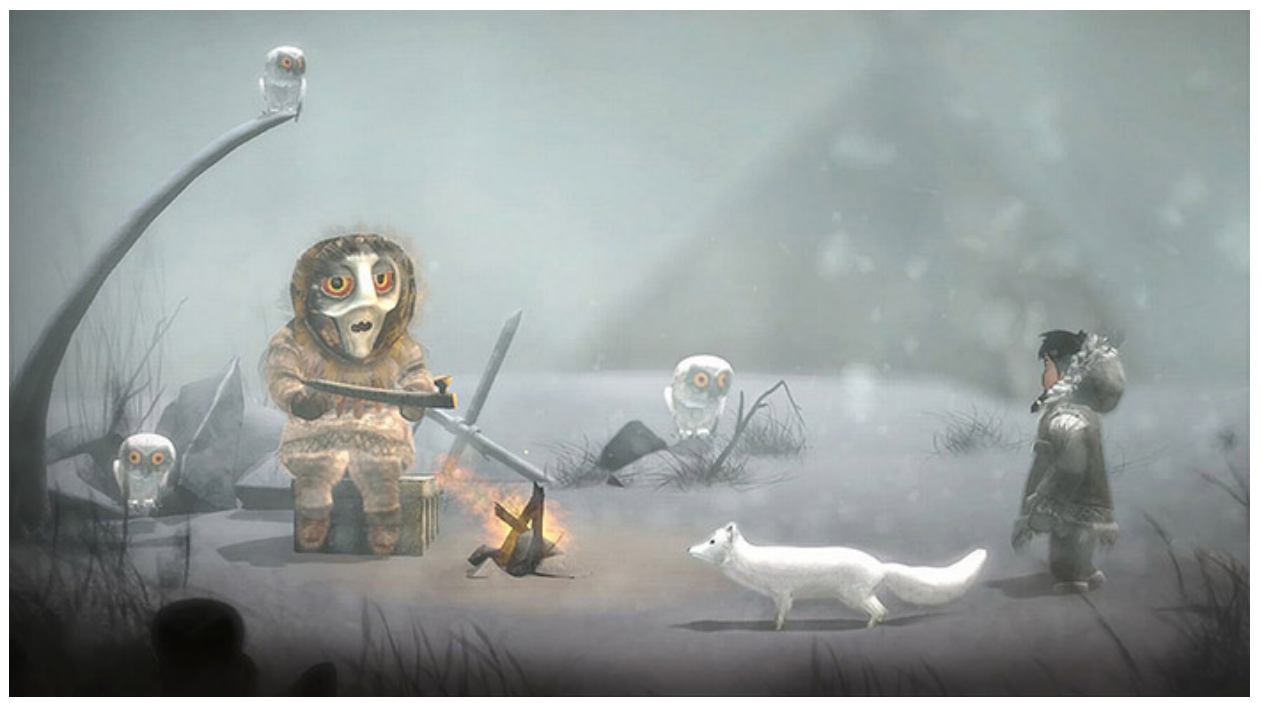

Fonte: Shamp (2016).

\section{CONCLUSÃO}

Em certos momentos da história dos jogos, os mesmos foram usados como uma mídia onde racismo, sexismo e classicismo apareciam aplicados e aparentemente tolerados como algo pouco problemático devido à importância e condições significativas dos jogos em determinadas culturas (FLANAGAN, 2009). Hoje, entende-se que o olhar para os jogos do passado é importante 
como uma forma de compreender as antigas aplicações dos mesmos, em contraste com a nova cultura que está sendo criada em torno desse mercado, envolvendo novas representações e significações culturais.

Designers e designers de jogos podem ajudar no processo de desenvolvimento e significação cultural dos jogos devido às questões específicas do processo de desenvolvimento desses produtos e também às características intrínsecas da linguagem do design, assim como às distintas possibilidades da mídia, sendo esta digital, não digital ou até mesmo em possíveis hibridismos. Entretanto, para que esse processo seja validado, é necessário que os mesmos invistam parte do tempo de produção das mídias em pesquisas variadas e adequadas à projetos específicos.

O processo de desenvolvimento da cultura de jogos é vivo, em constante transformação, e também é afetado pela tecnologia da época, conforme podemos observar nos exemplos digitais e não digitais citados, assim como na arte de Pieter Bruegel. Mídias interativas como Senet, Monopoly e Never Alone, da mesma forma que personagens como Mario e Pac-Man refletem e são reflexos de uma constante ressignificação cultural. Esse intercâmbio cultural molda a nossa percepção em relação aos jogos, porque estes dependem de fatores históricos, sociais e regionais que contribuem para o seu constante processo de ressignificação cultural. É possível notar, por exemplo a mudança cultural entre os jogos desenvolvidos nos Estados Unidos no final do século $\mathrm{XIX}$ os quais visavam preparar, educar e treinar as pessoas para tarefas do cotidiano, inclusive possíveis participações em guerras, e as mídias atuais, que buscam proporcionar experiências distintas, por vezes emocionais e sensoriais, a partir de elementos do cotidiano ou da experimentação de culturas distintas.

Dessa forma, entende-se que um enfoque cultural dos jogos é importante como forma de mapeamento e compreensão do produto como uma ferramenta de significação cultural socialmente ativa, formada a partir do seu design, considerando a influência de diversas culturas. 


\section{REFERÊNCIAS}

ASHCRAFT, Brian. The games that changed Japan. 2012. Disponível em: <https://www.theguardian.com/travel/2012/feb/01/tokyo-japan-gamingculture-games>. Acesso em: 1 jun. 2017.

BARTELSON, Eric. Empathy games: birth of a genre? Disponível em: <http:// ctrl500.com/developers-corner/empathy-games-•-fighting-tears/>. Acesso em: 31 maio 2017.

BOGOST, Ian. Electronic mediations: how to talk about videogames. Minneapolis: University Of Minnesota Press, 2015.

FLANAGAN, Mary. Critical play: radical game design. Cambridge: MIT press, 2009.

FRANK, Allegra. A chronological history of Pokémon games. 2016. Disponível em: <https://www.polygon.com/pokemon/2016/2/26/11120098/pokemongames-list-history-timeline-release-dates>. Acesso em: 31 maio 2017.

GANDOLFI, Enrico. To watch or to play, it is in the game: the game culture on Twitch.tv among performers, plays and audiences. Journal of Gaming \& Virtual Worlds, Alberta, v. 8, n. 1, p. 63-82, Mar. 2016.

GRANT, Jordan. Board games have been teaching us how to shop for more than a century. 2015. Disponível em: <http://americanhistory.si.edu/blog/ board-games-teaching-us-to-shop>. Acesso em: 31 maio 2017.

HANSEN, Dustin. Game On!: video game history from pong and Pac-Man to Mario, Minecraft, and more. New York: Macmillan, 2016.

HARRIS, Blake J. A guerra dos consoles: sega, nintendo e a batalha que definiu uma geração. Rio de Janeiro: Intrínseca, 2014.

ISBISTER, Katherine. How games move us: emotion by design. Cambridge: Mit Press, 2016.

JULL, Jesper. A casual revolution: reinventing video games and their players. Cambridge: Mit Press, 2010.

MCGONIGAL, Jane. Reality is broken: why games make us better and how they can change the world. New York: The Penguin Press, 2011. 
MOREIRA, Matheus. O robô que superou os campeões de Go, jogo milenar chinês. 2017. Disponível em: <https://www.nexojornal.com.br/ expresso/2017/05/29/O-robô-que-superou-os-campeões-de-Go-jogomilenar-chinês>. Acesso em: 30 maio 2017.

PHILLPS, Tom. How 9/11 changed grand theft auto 3. 2011. Disponível em: <http://www.eurogamer.net/articles/2011-11-18-rockstar-how-9-11-changedgrand-theft-auto-3>. Acesso em: 31 maio 2017.

PILON, Mary. The secret history of monopoly: the capitalist board game's leftwing origins. 2015. Disponível em: <https://www.theguardian.com/ lifeandstyle/2015/apr/11/secret-history-monopoly-capitalist-game-leftwingorigins>. Acesso em: 31 maio 2017.

SCHIESEL, Seth. Classes turn to video game that works legs. 2007. Disponível em: <http://www.nytimes.com/2007/04/30/health/30exer.html>. Acesso em: 31 maio 2017.

SHAMP, Austin. Never alone: october game of the month. 2016. Disponível em: <http://www.gamecolab.com/single-post/2016/10/05/Never-AloneOctober-Game-of-the-Month>. Acesso em: 31 maio 2017.

SILVEIRA, Guaracy Carlos. Jogos digitais como ferramenta cultural: uma proposta interdisciplinar. In: SB GAMES, 15., 2016, São Paulo. Proceedings... São Paulo, 2016. p. 880-888. Disponível em: <http://www.sbgames.org/ sbgames2016/downloads/anais/157228.pdf>. Acesso em: 19 maio 2017.

VILHELMSEN, Lars. Business risk-tool. 2017. Disponível em: <http://workz.dk/ posts/business-risk-tool>. Acesso em: 31 maio 2017.

VON DOVIAK, Scott. Atari: game over is a nostalgic excavation of video-game history. 2015. Disponível em: <http://www.avclub.com/review/atari-gameover-nostalgic-excavation-video-game-hi-217925>. Acesso em: 30 maio 2017.

WIKIMEDIA COMMONS. Pieter Bruegel the Elder. Disponível em: <https:// commons.wikimedia.org/wiki/File:Pieter_Bruegel_the_Elder_-_Children's_ Games_-_Google_Art_Project.jpg>. Acesso em: 30 maio 2017. 